\title{
DIGITAL PEEK FRAMEWORK AND PATIENT SATISFACTION COMPARED TO CONVENTIONAL METAL FRAMEWORK IN REMOVABLE PARTIAL DENTURES. A CLINICAL TRIAL
}

\author{
Seham E. Mohamed* and Hashem Rasha G. **
}

\begin{abstract}
Introduction: Utilization of removable partial dentures (RPD) is inevitable in some patients that are not indicated for any other treatment option, thus patient satisfaction with this line of treatment is of great importance. However, a notable need exists to advance materials and fabrication technologies due to the undesirable health outcomes linked with current RPDs.
\end{abstract}

Aim: In this study patient satisfaction with conventionally manufactured metal RPD framework, was compared with their satisfaction using digitally milled PEEK (Juvora) framework.

Methods: Ten patients were selected having class I partially edentulous mandibles. A conventional metal framework RPD was constructed for each patient, then another RPD with milled PEEK framework was digitally fabricated for each one of them. Each patient had the chance to use each denture for three months, then questionnaires were filled to assess their satisfaction.

Results: The questionnaires were statistically analyzed and resulted in more patients' satisfaction with the digital PEEK framework RPD, than with conventional metallic RPD framework.

Conclusion: PEEK material increases patients' satisfaction with RPDs than the conventional metal framework material, thus decreasing patients' complaints from removable appliances.

KEY WORDS: Digital workflow, CAD/CAM, digital RPD, PEEK (Juvora), distal extension RPD, patient satisfaction.

\section{INTRODUCTION}

Partially dentate adults' number is increasing compared to completely edentulous individuals, in part as a result of the expanded life anticipation, increase in number of elderly individuals due to rise in health care measures, and a shift from complete tooth loss toward partial edentulism ${ }^{(1,2,3)}$. The improvement in oral health resulted in people extracting fewer teeth, and increasingly needing treatment of partial rather than complete edentulism (2). Restoration of lost teeth and associated

* Lecturer in Removable Prosthodontics Department, Ahram Canadian University,

** PhD. of Removable Prosthodontics 
structures is important to, upgrade appearance, reinforce masticatory efficiency, prevent unwanted movements of teeth (overeruption/drifting) and improve phonetics. Quality of patient's life becomes better when aesthetics and functions of stomatognathic system are improved ${ }^{(4)}$.

Given the relation between edentulism (complete or partial) and low socioeconomic status, RPDs will probably represent an essential treatment option in comparison with more costly alternatives ${ }^{(5)}$. Thus RPDs exceeds conservative implant tooth replacements because of their accessibility to this low socioeconomic groups in whom the highest rates of missing teeth occurs ${ }^{(6)}$.

RPDs can be indicated to overcome financial restrictions, as interim prostheses, to ease hygiene access, or to overcome biomechanical and pragmatic matters associated with other restorative options (1). Long-span edentulous spaces are difficult to be replaced with fixed prostheses, resulting in poor prognosis. RPDs are also the best strategy for many clinical scenarios, such as substituting missing hard and soft tissues, that result in a need for esthetic support of the orofacial structures ${ }^{(1,7)}$. Free end RPDs are of the most critical situations in achieving long term success without endangering the remaining tissues, especially in the mandible as it has decreased amount of bony ridge ${ }^{(8)}$.

Patients seeking teeth replacement comes to the dental clinics with varying expectations and previous experiences. Patient satisfaction with the prosthesis can have a profound impact on the success of treatment, because dissatisfaction with a RPD will likely lead to disuse and subsequent rehabilitation failure ${ }^{(9)}$. In this respect, treatment of partially edentulous ridges with removable partial dentures is satisfactory for majority of cases ${ }^{(10)}$. No matter how skilled a professional is some patients are still not satisfied with RPDs, therefor patient acceptance of the prosthesis plays a major role in its success ${ }^{(11)}$. Satisfaction with the dental prosthesis is multifactorial, involving technical and patient related variables. Comfort, masticatory ability, aesthetics and retention seem to be the major factors for satisfaction with the prosthetic appliance ${ }^{(9,12)}$.

The benefits of metal-based frameworks over acrylic resin are, it can be utilized in thin sections with decreased bulk, has higher strength and stiffness, transmit heat and cold allowing natural tissues stimulation, allow designs that diminish gingival margins coverage, permit a stable denture base, undergo repassivation, and are resistant to corrosion ${ }^{(13)}$. Although cobalt-chromium is usually considered the best material for a denture framework, its physical properties are not ideal. Esthetically unacceptable display of metal clasps, increased prosthesis weight, potential for metallic taste, oral galvanism, osteolysis of abutment teeth, biofilm production and allergic reactions to metals have led to the introduction of a number of thermoplastic materials in clinical practice ${ }^{(1,13-15)}$.

Application of digital technology to removable and fixed prosthesis' design and construction, is advancing rapidly. Computer-aided design and computer-aided manufacturing (CAD-CAM) systems are being widely used in the design and construction of prosthodontics. CAD-CAM techniques have been tested as a technique of surveying 3D-scanned dental models to create RPD frameworks ${ }^{(4)}$. Different software types are used to design RPD frameworks. The main restriction hindering the wide application of a complete RPD digital workflow is the difficulty and expenses associated with the metal frameworks production ${ }^{(16)}$. Recent technology as 3D scanners and denture designing software modules promise improvements in RPD production ${ }^{(4)}$.

Digital dentistry in general utilizing CADCAM technology, high precision 3D printers and scanners, mass industrial casting and production techniques are predicted to enhance the fit, esthetics, and functional components of RPDs while reducing costs and effort, hence increasing potency and manufacturing outcomes ${ }^{(17)}$. 
Digital solutions grant the application of recent materials that would not be utilized for RPD fabrication, except digitally. Polymers are especially considered because of their ease of construction and desirable properties ${ }^{(16)}$.

Various developments of new polymers by modifying existing materials with the addition of fillers such as glass, silica, borosilicate, and fused quartz ${ }^{(18)}$. Some advantages of polymerbased frameworks over metal frameworks are their improvement of esthetics due to their translucency and color, more cost-effective, high elasticity, straightforward manufacturing, lightweight, low water sorption and solubility, and are easily repaired and reconstructed ${ }^{(13,15)}$.

One of the recently introduced materials in dentistry is the polyether ether ketone (PEEK) which is white, radiolucent, rigid material with great thermal stability ${ }^{(19)}$. It is non allergic with low plaque affinity ${ }^{(20)}$. PEEK's mechanical properties are not changed during sterilization, weather using steam, gamma and ethylene oxide ${ }^{(19)}$. Young's (elastic) modulus and tensile properties are close to human bone, enamel and dentin. Polyether ether ketone is resistant to hydrolysis, non-toxic and is one of the best biocompatible materials ${ }^{(19,20)}$. It has a special chemical structure, which exhibits stable chemical and physical properties with low water solubility and absorption ${ }^{(21)}$. Juvora disc made from PEEK-OPTIMA is a high performance polymer that can be used for long term fixed and removable restorations ${ }^{(20)}$.

\section{AIM}

The aim of this study is to evaluate patient satisfaction with an alternative treatment approach using digitally milled PEEK (Juvora) framework RPDs, and compare it with their satisfaction using conventional metal framework RPDs in patients having class I edentulous mandibles.

\section{MATERIALS AND METHODS:}

Ten partially edentulous patients were selected from the out-clinic, Faculty of Oral and Dental Medicine, Ahram Canadian University, having mandibular class I Kennedy classification seeking to restore their missing tissues. The patients' age group was ranged from 30 to 50 years, and they all had no previous experience in RPD wearing. Informed consent was obtained from each patient participating in the study.

Each patient was carefully diagnosed, and conventional RPD with $\mathrm{Cr}$ Co metal framework was constructed with the conventional technique. Patients were instructed to use their RPDs for three months, after all the follow up adjustments were finished. A questionnaire was filled by each patient to assess his satisfaction with the RPD considering retention, mastication, esthetics, hygiene, and comfort at the end of the three months.

Another RPD was digitally fabricated for each patient from milled PEEK (Juvora) material as a non-metallic framework. A duplicate from the patient's master cast was poured in extra hard stone (type IV, Elite Rock; Zhermack) to be scanned on the 3d scanner (Zirkonzahn S600 ARTI Scanner, Italy) with a scanning software, to create virtual model obtaining a standard tessellation language (STL) file format, which was then imported to the CAD soft-ware (3Shape Dental System, version 2.9.9.3) used to start the design process. The virtual model was digitally surveyed to delineate the survey line, determine the most suitable path of insertion, and block out all the undesirable undercuts. The framework was digitally designed on the virtual cast that resembles the $\mathrm{Cr}$ Co framework design with the exception of slight increase in thickness to allow for the desired rigidity needed for PEEK framework (Figure 1). The major connector was designed to be lingual plate not lingual bar as in the metal framework design to provide enough thickness of PEEK material. The characteristic 


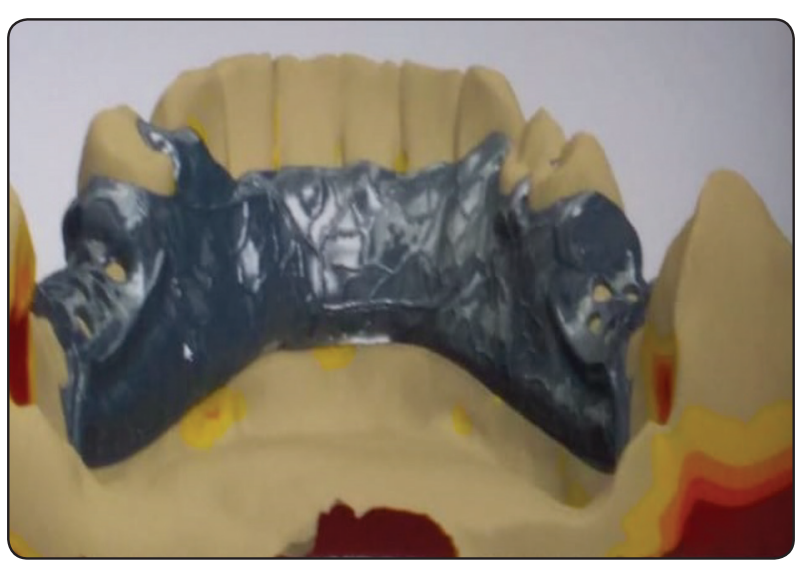

Fig. (1) Digitally designed framework

features of the framework, including the half pear shaped cross section of lingual plate, the internal and external finish lines, the tissue stops at the tissue surface of mesh construction were applied. The framework thickness was $0.8 \mathrm{~mm}$., as required per (PEEK) material mechanical properties. The design was then checked and reviewed to assure smooth and rounded margins and connections between the components. The design data on the STL file of the software was saved.

The framework was milled by the milling machine (Figure 2) (Roland DWX-50, 5-Axis Dental milling Machine, Chicago, USA) from a ready-made PEEK disc (Juvora Ltd., Technology center, Hilhouse International, Thornton Cleveleys, Lancashire, UK), which has no filler content,

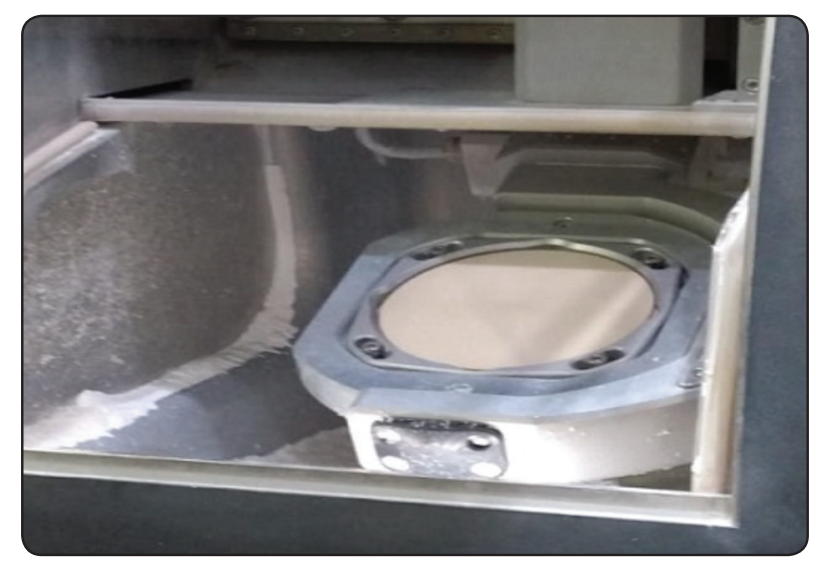

Fig. (2) The milling machine then finishing and polishing was conducted. The framework was tried in the oral cavity and checked for accuracy of adaptation, then the subsequent steps were conducted according to the conventional techniques. Patients were instructed to use the PEEK dentures for three months after the last follow up adjustments conducted, then the same questionnaire was filled (Figure 3).

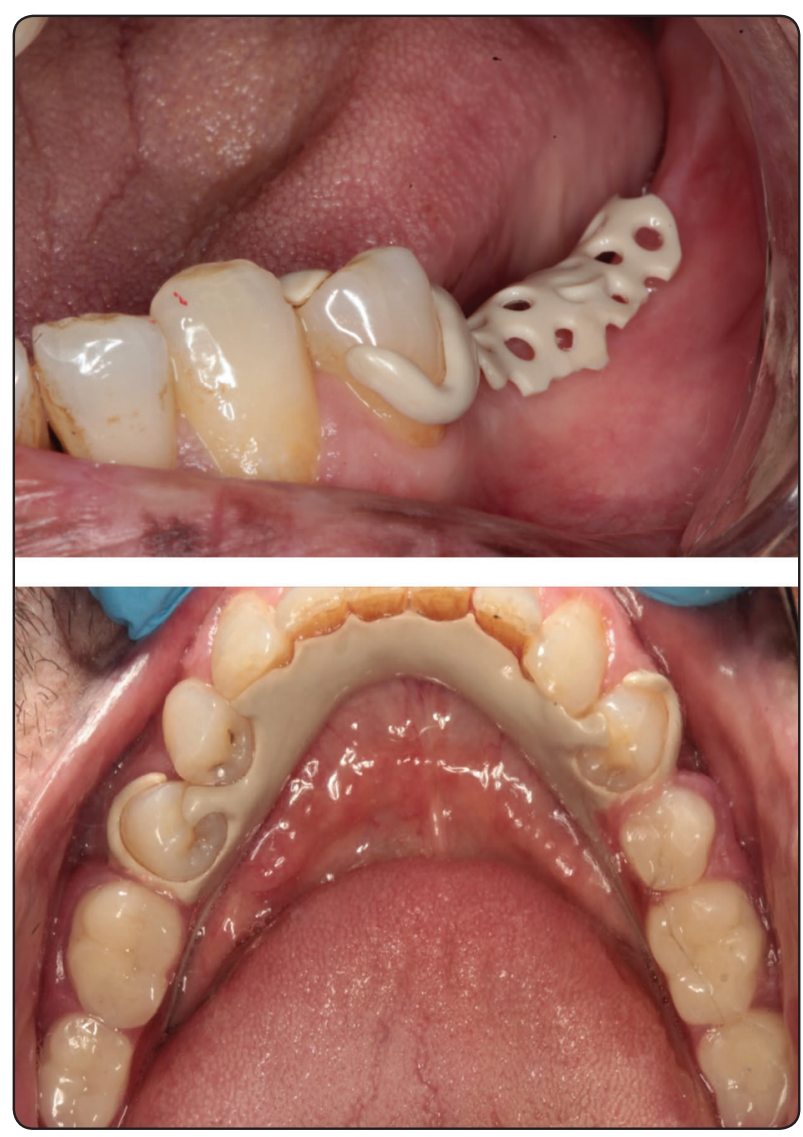

Fig. (3) PEEK RPD in patient's mouth

Patient satisfaction was compared from the questioners obtained after. The questioner used in this study was the Arabic version of the Oral Health Impact Profile in edentulous patients (OHIPEDENT) the 19 questions form, which evaluates quality of patients' live and their satisfaction with the prosthetic appliance. The OHIP-EDENT questioner evaluates functional limitations, physical pain or disability, psychological discomfort or disability, 
social disability and handicap. It is recognized by the WHO as an important segment of the Global Oral Health Program (2003) ${ }^{(22)}$.

Data was tabulated and analyzed. Statistical analysis of the obtained data was conducted by the use of ANOVA (analysis of variance) test to detect if there was significant difference between patients' satisfaction with each type of frameworks. Duncan;s (Duncan's multiple range) test was then applied to distinguish which type of frameworks was more satisfying to the patients under this investigation.

\section{RESULTS}

During the conduction of this study, some patients complained from the unaesthetic display of metal with the conventional metal frameworks RPDs before the conduction of the questioner and preferred to have RPDs with more esthetic nonmetallic show and tooth colored frameworks.

Most of the patients under this investigation were more accepting the idea of using a removable device with a non-metal framework, for the avoidance of metallic taste and the galvanism experienced with the metal frameworks.

Considering PEEK frameworks (Table 1), it was found that concerning functional limitation, $30 \%$ of the patients indicated difficulty in chewing foods sometimes. In physical pain, 50\% of patients experienced painful aching rarely, in physical disability, $40 \%$ of patients rarely avoided eating some foods because of problems with their dentures.

In psychological discomfort, $55 \%$ of patients indicated never being worried by dental problems, in psychological disability, $40 \%$ of patients have never been unable to eat. In social disability, $70 \%$ of patients have never avoided going out, and in handicap, $75 \%$ of patients have never been unable to enjoy company and unsatisfied.

Considering metal frameworks (Table 2), it was found that concerning functional limitation, $30 \%$ of the patients indicated difficulty in chewing foods often. In physical pain, $40 \%$ of patients experienced painful aching sometimes, in physical disability, $60 \%$ of patients avoided eating some foods sometimes because of problems with their dentures. In psychological discomfort, $35 \%$ of patients indicated rarely being worried by dental problems, in psychological disability, $35 \%$ of patients have rarely been unable to eat. In social disability, $47 \%$ of patients have rarely avoided going out, and in

Table (1) Questioner answers for PEEK frameworks

\begin{tabular}{|c|c|c|c|c|c|}
\hline $\begin{array}{c}\text { PEEK } \\
\text { Frameworks }\end{array}$ & Never & Rarely & Sometimes & Often & Always \\
\hline $\begin{array}{c}\text { Functional } \\
\text { limitation }\end{array}$ & $20 \%$ & $30 \%$ & $30 \%$ & $20 \%$ & 0 \\
\hline Physical pain & $30 \%$ & $50 \%$ & $10 \%$ & $10 \%$ & 0 \\
\hline $\begin{array}{c}\text { Physical } \\
\text { disability }\end{array}$ & $10 \%$ & $40 \%$ & $30 \%$ & $10 \%$ & $10 \%$ \\
\hline $\begin{array}{c}\text { Psychological } \\
\text { discomfort }\end{array}$ & $55 \%$ & $25 \%$ & $5 \%$ & $15 \%$ & 0 \\
\hline $\begin{array}{c}\text { Psychological } \\
\text { disability }\end{array}$ & $40 \%$ & $35 \%$ & $10 \%$ & $15 \%$ & 0 \\
\hline $\begin{array}{c}\text { Social } \\
\text { disability }\end{array}$ & $70 \%$ & $20 \%$ & $10 \%$ & 0 & 0 \\
\hline Handicap & $75 \%$ & $5 \%$ & $15 \%$ & $5 \%$ & 0 \\
\hline
\end{tabular}

Table (2) Questioner answers for metal frameworks

\begin{tabular}{|c|c|c|c|c|c|}
\hline $\begin{array}{c}\text { Metal } \\
\text { Frameworks }\end{array}$ & Never & Rarely & Sometimes & Often & Always \\
\hline $\begin{array}{c}\text { Functional } \\
\text { limitation }\end{array}$ & 0 & $30 \%$ & $20 \%$ & $30 \%$ & $20 \%$ \\
\hline Physical pain & $10 \%$ & $30 \%$ & $40 \%$ & $20 \%$ & 0 \\
\hline $\begin{array}{c}\text { Physical } \\
\text { disability }\end{array}$ & 0 & $10 \%$ & $60 \%$ & $20 \%$ & $10 \%$ \\
\hline $\begin{array}{c}\text { Psychological } \\
\text { discomfort }\end{array}$ & $15 \%$ & $35 \%$ & $30 \%$ & $15 \%$ & $5 \%$ \\
\hline $\begin{array}{c}\text { Psychological } \\
\text { disability }\end{array}$ & $5 \%$ & $35 \%$ & $30 \%$ & $25 \%$ & $5 \%$ \\
\hline $\begin{array}{c}\text { Social } \\
\text { disability }\end{array}$ & $40 \%$ & $47 \%$ & $10 \%$ & $3 \%$ & 0 \\
\hline Handicap & $35 \%$ & $35 \%$ & $30 \%$ & 0 & 0 \\
\hline
\end{tabular}


handicap, $35 \%$ of patients have never been unable to enjoy company and unsatisfied.

Statistical analysis was conducted by the use of ANOVA test of the answered questioner for each patient about his conventional metallic framework RPD and his milled PEEK (Juvora) framework RPD, at a confidence interval of $95 \%$ and the null hypothesis (meaning there was no difference in patients' satisfaction between the two denture types) was rejected, which means that there is significant difference in patient satisfaction values between the conventional metal framework RPDs and the Juvora PEEK framework RPDs. Duncan's multiple range test was conducted to differentiate between means of the patients' answers to evaluate the degree of patients' satisfaction with each RPD type. Duncan's test revealed that patients were more satisfied with the milled PEEK (Juvora) framework RPD than with conventional metallic framework RPD. The mean of overall patients' satisfaction in case of PEEK framework was found to be $1.98 \pm 0.51$, and the mean of overall patients' satisfaction in case of metal frameworks was found to be $2.0 \pm 0.51$.

\section{DISCUSSION}

In the current study patients were treated with RPDs to restore function and improve their quality of life which is in agreement with Campbell et. al. (16) who stated that, treatment with RPDs should ideally results in improvements in overall oral health, patient satisfaction, and compliance. Design, materials, ease of repair, patient education, and followup for RPD treatment all are pragmatic issues that have a significant impact on treatment success.

This study aim was to evaluate patient satisfaction, in which Cimas et. al. ${ }^{(23)}$ stated that, research on quality of health care and patient satisfaction is constantly increasing nowadays. Carlsson ${ }^{(24)}$ stated that, considering that patient satisfaction is the ultimate objective during oral rehabilitation, it is interesting to note that few studies were performed to verify and understand the factors that affect this satisfaction.
Patients under this investigation were found to be more satisfied with PEEK frameworks than with metal frameworks in denture retention and stability, which is in agreement with Keltjens et. al. ${ }^{(25)}$ who stated that, retainers (metal clasps) after 8 years of normal use were found to be distorted and that over time they did not fit the abutment correctly. On the contrary Tannous et. al. ${ }^{(26)}$ stated that, clasps made of PEEK have lower resistance forces than the ones made from cobalt - chrome.

Using digitally fabricated milled PEEK frameworks was conducted to allow more adaptation of the prosthesis and better retention, and this is in accordance with Campbell et. al. and Harb et. al. ${ }^{(16,27)}$ who stated that, digital strategies widen the scope of therapeutic applications for partial dentures as a result of improved design and production control, new materials, and improved efficiencies with adequate fit that will likely enhance outcomes and improve patient experiences. However, digital fabrication is higher in cost than the conventional lost-wax fabrication technique and metallic RPD frameworks, thus it may be restricted for partially edentulous patients with financial constraints.

It was found in this study that patients were more satisfied with PEEK frameworks which was in accordance with Skirbutis et. al. ${ }^{(28)}$ who mentioned that mechanical properties of PEEK are similar to dentin and enamel, thus it has superiority over metal alloys and ceramic restorations, as PEEK has high fracture load resistance, it is suitable for producing frames.

Harbet.al. ${ }^{(27)}$ also concluded that, the low specific weight of PEEK material permits the fabrication of lighter prostheses with good functionality, this will be in agreement with the results of our study.

Stawarczyk et. al. ${ }^{(29)}$ reported that, PEEK matrix with no filler content was found to be more stable than with fillers in the nanoscale range. Jouvora material is the purest form of PEEK without filler thus used safely in the oral cavity. 
On the contrary a study by Zoidis et. al. (20) concluded that, in the absence of more clinical studies along with some concerns about PEEK's behavior under fatigue stresses during use, suggests that it should still be used with caution and yet cannot be recommended as an alternative to cobaltchromium frameworks.

In the present study, the questionnaire used was in agreement with Dervis ${ }^{(30)}$, in which it included all the necessary parameters related to dentures functionality, possible occurrence of pain, and the psychological and social aspects of their use. The answers to these questions are a clear indication of how patients feel about their dentures.

Raina et. al. ${ }^{(31)}$ reported that, the poor self-perceived satisfaction among denture wearers affect their quality of life. There was no difference found in the patients' satisfaction between patients with their first ever RPD and the patients who had previous experience ${ }^{(32)}$. Shetty et al ${ }^{(11)}$ when studied patient satisfaction with RPDs, reported that when comfort with chewing, laughing, swallowing, inserting or removing the denture was evaluated, 9.6\% were comfortable with the prosthesis, $22 \%$ were satisfied with the appearance, and only $1 \%$ of the subjects were found to be satisfied with the retention and stability.

The limitations of the present study include a small sample size as well as the use of a quantitative approach and correlation-based analysis, which limits the evaluation of a cause-effect relationship among the evaluated variables.

\section{CONCLUSION}

Digitally fabricated removable partial denture frameworks made of PEEK (Juvora) material allows removable partial denture patients to be more satisfied with their prosthesis than conventional metal frameworks, thus extending the application of removable partial dentures and decreasing patients' rejection to the removable appliances, which will serve to restore more partially edentulous cases with great satisfaction and least complaints.

\section{REFERENCES}

1. Benso B., Kovalik A. C., Jorge J. H., et al.: Failures in the rehabilitation treatment with removable partial dentures. Acta Odontolgia Scandnevian. 2013; 71: 1351-1355.

2. Douglass C. W. and Watson A. J.: Future needs for fixed and removable partial dentures in the United States. Journal of Prosthetic Dentistry. 2002; 87: 9-14.

3. Allen P. F. and McMillan A. S.: A review of the functional and psychosocial outcomes of edentulousness treated with complete replacement dentures. Journal of Canadian Dental Association. 2003; 69(10): 662-662e.

4. Bohnenkamp D. M.: Removable partial dentures: clinical concepts. Dental Clinical Northen American. 2014; 58: 69-89.

5. Preshaw P. M., Walls A. W., Jakubovics N. S., et al.: Association of removable partial denture use with oral and systemic health. Journal of Dentistry. 2011; 39: 711-719.

6. Ramamoorthi M. and Khuraif A. A. A.: A Comparative evaluation of fatigue behavior of removable partial denture alloys with and without heat treatment. International Journal of Dental Clin. 2011; 3(1): 14-17.

7. Mazurat N. M. and Mazurat R. D.: Discuss before fabricating: communicating the realities of partial denture therapy. Part I: patient expectations. Journal of Canadian Dental Association. 2003; 69: 90-94.

8. Manumeet B., Jitender B., Gyanander A., et al.: A review on stresses- induced by removable partial dntures. International Journal of Contemporary Dentistry Medicine Rev. 2015; 10: 1-5.

9. Koyama S., Sasaki K., Yokoyama M., et al.: Evaluation of factors affecting the continuing use and patient satisfaction with removable partial dentures over 5 years. Journal of Prosthetic Research 2010; 54: 97-101.

10. Sharma A. and Tabassum A.: Evaluation of patient satisfaction for retention, masticatory efficacy, aesthetics and comfort for removable partial denture: A retrospective study. International Journal of Applied Dental Sciences. 2018; 4(1): 91 -93.

11. Shetty M. S., Panchamal G. S. and Shenoy K.: Patient satisfaction with removable partial dentures and related factors - A pilot study. Journal of Contemporary Medicine. 2015; 5(1): 13-17.

12. Ducia C. C., Simone M. B., Eduardo D. L. F., et al.: Functional evaluation of oral rehabilitation with removable 
partial dentures after five years. Journal of Applied Oral Scince. 2006; 14(2): 111-116.

13. Wiesli M. G. and Ozcan M.: High-performance polymers and their potential application as medical and oral implant materials: a review. Implant Dentistry. 2015; 24: 448-457.

14. Behr M., Zeman F. and Passauer T.: Clinical performance of cast clasp-retained removable partial dentures: A retrospective study. International Journal of Prosthodontics. 2012; 25: 138-144.

15. Schwitalla A. D., Spintig T., Kallage I., et al.: Flexural behavior of PEEK materials for dental application. Dental Materials. 2015; 31: 1377-1384.

16. Campbell S. D., Cooper L., Craddock H., et al.: Removable partial dentures: The clinical need for innovation. Journal of Prosthetic Dentistry. 2017; 118(3): 273-280.

17. Bilgin M. S., Baytaroglu E. N., Erdem A., et al.: A review of computer-aided design/computer-aided manufacture techniques for removable denture fabrication. Eurepian Journal of Dentistry. 2016; 10: 286-291.

18. Bhola R., Bhola S. M., Liang H., et al.: Biocompatible denture poymers-a review. Trends Biomater. Artif. Organs. 2010; 23: 129-136.

19. Monich P. R., Berti F. V., Porto L. M., et al.: Physicochemical and biological assessment of PEEK composites embedding natural amorphous silica fibers for biomedical applications. Material Science Engineering Clinical Material Biological Application. 2017; 79: 354-362.

20. Zoidis P., Papathanasiou I. and Polyzois G.: The Use of a modified poly ether ether ketone (PEEK) as an alternative framework material for removable dental prostheses. A clinical report. Journal of Prosthetic Dentistry. 2016; 25(7): 580-584.

21. Liebermann A., Wimmer T., Schmidlin P. R., et al.: Physicomechanical characterization of polyetheretherketone and current esthetic dental CAD/CAM polymers after aging in different storage media. Journal of Prosthetic Dentistry. 2016; 115: 321-328.
22. Sischo L. and Broder H. L.: Oral health-related quality of life: What, why, how, and future implications. Journal of Dental Research. 2011; 90: 1264-1270.

23. Cimas M., Ayala A., Garcia-Perez S., et al.: The patient satisfaction questionnaire of EU primecare project: measurement properties. International Journal of Quality in Health Care. 2016; 28(3): 275-280.

24. Carlsson E. G.: Facts and fallacies: an evidence base for complete dentures. Dental Update. 2006; 33: 134-136.

25. Keltjens H. M., Mulder J., Kayser A. F., et al.: Fit of direct retainers in removable partial dentures after 8 years of use. Journal of Oral Rehabilitation. 1997; 24: 134-142.

26. Tannous F., Steiner M., Shahin R., et al.: Retentive forces and fatigue resistance of thermoplastic resin clasps. Dental Materials Journal. 2012; 28: 273-278.

27. Harb I. E., Abdel-Khalek E. A. and Hegazy S. A.: CAD/ CAM constructed polyether ether ketone (PEEK) framework of Kennedy class I removable partial denture: A clinical report. Journal of Prosthodontics. 2018: 1-4.

28. Skirbutis G., Dzingutė A., Masiliūnaitè V., et al.: A review of PEEK polymer's properties and its use in prosthodontics. Stomatologija Baltic Dental and Maxillofacial Journal. 2017; 19: 19-23.

29. Stawarczyk B., Eichberger M., Uhrenbacher J., et al.: Three-unit reinforced polyetheretherketone composite FDPs: Influence of fabrication method on load-bearing capacity and failure types. Dental Materials Journal. 2015; 34: 7-12.

30. Dervis E.: Clinical assessment of common patient complaints with complete dentures. European Journal of Prosthodontics Restorative Dentistry. 2002; 10: 113-117.

31. Raina K., Gupta B. D., Gupta R., et al.: Self-reported oral health and denture satisfaction in partially and completely edentulous patients. Journal of Indian Association Public Health Dentistry. 2019; 17: 54-57.

32. Knezovid Zlatarid D., Čelebid A, Valentid-Peruzovid M., et al.: A survey of treatment outcomes with removable partial dentures. Journal of Oral Rehabilitation 2003; 30(8): 847-854. 